\title{
Peripheral inactivation of gentamicin
}

\author{
P. Vaudaux \\ Infectious Disease Division, Department of Medicine, University Hospital, \\ 1211 Geneva 4, Switzerland
}

\begin{abstract}
Peripheral inactivation of aminoglycosides is defined as a reversible process related to the specific physico-chemical conditions prevailing in abscesses. Conditions of reduced $\mathrm{pH}$ and $\mathrm{pO}_{2}$, such as are found frequently within abscesses, may reduce strongly the antibacterial effect of aminoglycosides, possibly by their interfering action on aminoglycoside transport into the bacteria. In addition, binding factors in purulent exudates, such as leukocyte chromatin exposed to any aminoglycoside after cell lysis, may bind a significant proportion of the total antibiotic, leading to an equivalent decrease of the concentration of the free, biologically active drug. In contrast, intact phagocytes, which do not bind aminoglycosides on their chromatin because of drug exclusion from the viable cells, protect ingested bacteria from being killed by large amounts of antibiotics. The role played by the different inactivating factors has yet to be defined in a clinical context, by analysis of experimental abscesses as an extension of the present invitro data.
\end{abstract}

L'inactivation périphérique des aminosides est définie comme un processus réversible lié aux conditions physico-chimiques locales des sites infectés. L'abaissement du $\mathrm{pH}$ et de la $\mathrm{pO}_{2}$, fréquemment décrit au niveau des abcès, peut réduire fortement l'activité antibactérienne des aminosides, en réduisant l'accumulation intracellulaire de ces antibiotiques par les bactéries. D'autre part, on observe un effet de captation des aminosides par des constituants du matériel purulent, en particulier par la chromatine des neutrophiles lysés. Cette captation diminue la concentration d'antibiotique libre qui seule est biologiquement active. Par contraste avec les neutrophiles lysés, les neutrophiles vivants ne captent pas les aminosides au niveau de leur chromatine et protègent les bactéries qu'ils ont phagocytés de l'effet bactéricide des aminosides. Ces effets semblent être dûs à l'absence de pénétration des aminosides à l'intérieur des neutrophiles vivants. L'importance clinique de ces différents facteurs inactivant les aminosides n'est pas encore établie, en l'absence de données expérimentales obtenues chez l'animal.

\section{Introduction}

It is a trivial statement that antibiotics must accumulate inside infected areas or abscesses at levels exceeding the so-called minimal inhibitory or bactericidal concentration (MIC/MBC), in order to be effective against bacterial invaders. Penetration of antibiotics into infected tissues is markedly influenced by the type of 
infection, the bacterial species and the time course of the disease, and may be significantly impaired in situations of vascular obstruction and necrosis. In this context, no pharmacokinetic model can safely predict the antibiotic level inside a necrotic focus or an abscess, nor can it substitute for the need to assay the antibiotic level in a sampie of necrotic tissue or purulent exudate. If applied to the latter condition, such estimates of local antibiotic concentrations are often impaired by difficulties in collecting purulent samples of good quality and/or by possible interfering effects of the purulent exudate itself on the antibiotic assay.

Accordingly, this discussion is focussed on situations where antibiotic concentrations can easily be assayed in purulent exudates. Local inactivation of gentamicin will be assumed when adequate concentrations of the drug can be demonstrated, but these are unable to reduce significantly the viable counts of sensitive microorganisms. This definition does not imply that the drug itself is modified chemically, but means only that the environment is unfavourable to a proper action of the antibiotic on the target bacteria. The studies performed on experimental subcutaneous abscesses in rats by Dreznik et al. (1979) are an example. Abscess formation was induced by implantation of dialysis tubes contaminated on their surfaces with $4 \times 10^{7} \mathrm{cfu}$ of Pseudomonas aeruginosa. Seventy-two hours after implantation and development of the abscess, gentamicin $(10 \mathrm{mg} / \mathrm{kg})$ was injected intramuscularly and recovered in fairly good amounts (around $10 \mathrm{mg} / \mathrm{l}$ ) in abscess fluid for several hours. The bactericidal activity of gentamicin within the abscess was, however, insignificant, despite antibiotic levels well above the MIC $(0.8 \mathrm{mg} / \mathrm{l})$ of the infective organism. Because gentamicin was present in significant amounts when the drug was reassayed in suitable buffer conditions outside the abscess environment, the local inactivation of gentamicin could be considered as mainly a reversible process. Two major physico-chemical factors influence the gentamicin antibacterial activity in a reversible way, namely $\mathrm{pH}$ and $\mathrm{pO}_{2}$ of the surrounding medium. Intact or lysed leukocytes may also interfere with the antibacterial action of gentamicin in a purulent exudate. The role of gentamicin-modifying enzymes is not discussed as they are described in other presentations. It is hoped that this paper will show convincingly that the presence of assayable antibiotic in a sample of purulent exudate cannot be taken as evidence that the antibiotic is bioactive locally.

\section{General Comments}

The $\mathrm{pH}$ effect on gentamicin antibacterial activity is very difficult to describe accurately. The $\mathrm{p} K$ data for gentamicin are rather complex, because this aminoglycoside has three different components, namely $C_{1}$, and $C_{1 a}$ and $C_{2}$ : each component has five $\mathrm{p} K$ values related to its five nitrogen groups. This situation is too complex to allow an exact prediction of the respective fractions of uncharged, partially charged or fully charged drug molecules which are mixed together at the different $\mathrm{pH}$. At least, we can predict that the three components of gentamicin become increasingly ionized when the $\mathrm{pH}$ decreases. Such increase in ionization of gentamicin molecules is correlated in some way with the observed reduction of their antibacterial activity with falling $\mathrm{pH}$. Unfortunately, such reduction cannot be quantified with accuracy, because changes in MIC and MBC are neither sensitive, nor accurate parameters. Changes in $\mathrm{MIC}$ and $\mathrm{MBC}$ with changes in $\mathrm{pH}$ vary widely according to different investigators (Barber \& Waterworth, 1966; Sabath \& 
Toftegaard, 1974; Strausbaugh \& Sande, 1978; Paisley \& Washington, 1979), possibly because of differences in assay systems and in the species of the bacteria tested. There seems to be a twofold increase in MIC from pH 7.4-7.0 (Barber \& Waterworth, 1966; Paisley \& Washington, 1979). From pH 7.4-6.5 the increase in MIC may be as low as two-fold for some strains (Sabath \& Toftegaard, 1974) fourfold for other strains (Barber \& Waterworth, 1966; Sabath \& Toftegaard, 1974), or occasionally 8-fold and 16-fold for individual strains (Young \& Hewitt, 1973; Strausbaugh \& Sande, 1978) (Table). In this context, it should be recalled that $\mathrm{pH}$ estimates inside purulent exudates may vary widely from 7·2-6.2 (Hays \& Mandell, 1974). Therefore, no general statement can be made as to the degree of local inactivation of gentamicin's antibacterial activity as a function of falling $\mathrm{pH}$, since this inactivation may vary from $<20 \%$ at $\mathrm{pH} 7 \cdot 2$ to $>80 \%$ at $\mathrm{pH} 6 \cdot 2$.

The effect of reduced $\mathrm{pO}_{2}$ on the antibacterial activity of gentamicin cannot be accounted for by any physico-chemical modification of the drug itself. This effect has therefore to be explained at the level of the target bacteria. If we consider the different species of bacteria, it will be noticed that aerobic bacteria are very sensitive to gentamicin, whereas anaerobic bacteria like Clostridium perfringens and Bacteroides fragilis are not (Bryan, Kowand \& Van den Elzen 1979). Facultative bacteria growing anaerobically are more resistant to gentamicin (Bryan \& Van den Elzen, 1975) than when growing aerobically. In earlier studies, MIC determinations were quite difficult to perform in anaerobic conditions because of the unstable $\mathrm{pH}$ resulting from the production of acid metabolites by the bacteria (Rosenblatt \& Schoenknecht, 1972; Reynolds, Hamilton-Miller \& Brumfitt, 1976). Therefore, the effect of reduced $\mathrm{pO}_{2}$ could often not be differentiated in vitro from the effect of the falling $\mathrm{pH}$, and such technical problems are also encountered when the local inactivation of gentamicin occurring in vivo is considered for example within abscesses, where low $\mathrm{pH}$ and reduced $\mathrm{pO}_{2}$ frequently coexist (Hays \& Mandell, 1974).

A better understanding of the specific effect of reduced $\mathrm{pO}_{2}$ on the susceptibility of target bacteria to the drug, stems from detailed transport studies of this aminoglycoside across the cell wall into the bacteria (Bryan, Haraphongse \& Van den Elzen, 1976; Bryan et al., 1980; Bryan \& Van den Elzen, 1975, 1977). The correlation of increased intracellular accumulation of gentamicin with high sensitivity of the bacteria to the drug is good (Bryan et al., 1976, 1980; Bryan \& Van den Elzen, 1975, 1977). Experimental data show further that neither strictly anaerobic bacteria (Bryan et al., 1979) nor facultative bacteria growing anaerobically (Bryan \& Van den Elzen, 1975) can accumulate bactericidal levels of gentamicin. In contrast to these results, aerobic bacteria or facultative bacteria grown in aerobic conditions (Bryant et al., 1976, 1980; Bryan \& Van den Elzen, 1975, 1977) rapidly accumulated toxic levels of gentamicin, which thereafter could interact with ribosomes and which could lead eventually to cell death. With the use of metabolic inhibitors and of metabolic bacterial mutants, Bryan and his colleagues (Bryan et al., 1976, 1980; Bryan \& Van den Elzen, 1975, 1977) could demonstrate an absolute requirement for energy-dependent transport for gentamicin accumulation. This energy had to be generated by oxidative phosphorylation and could not be substituted by ATP produced under anaerobic conditions.

These findings show the essential role of some carrier components of the cytoplasmic membrane in gentamicin transport, connected in some way with the 


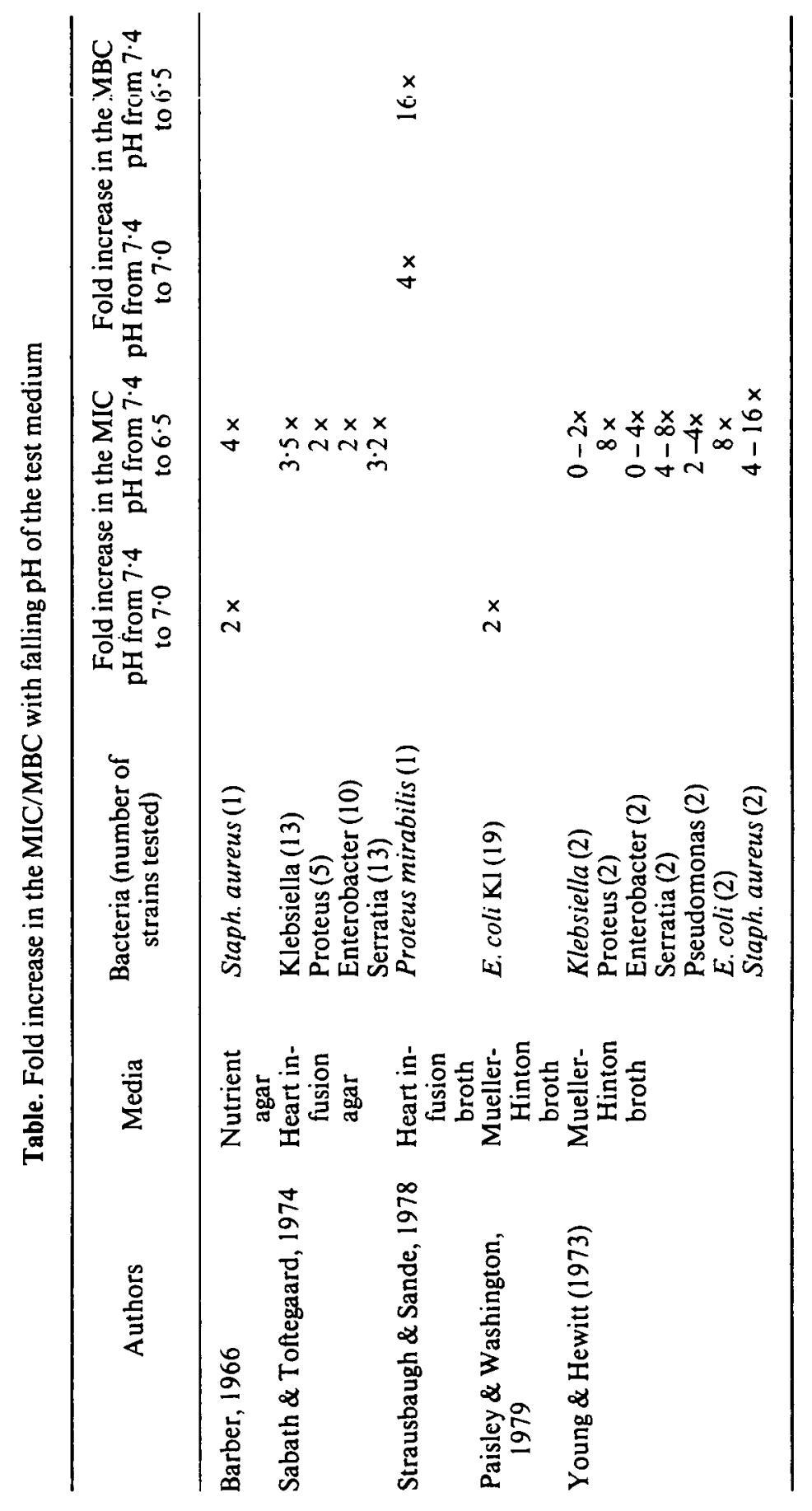


terminal electron transport system (Bryan \& Van den Elzen, 1977; Bryan et al., 1980). The presence or absence of these carriers, which are at present suspected to be respiratory quinones, seems to determine whether the bacteria will be able to accumulate the gentamicin molecules, and consequently to be sensitive to this drug (Bryan et al., 1980). Gentamicin transport is assumed (Bryan \& Van den Elzen, 1977; Bryan et al., 1980) to be relatively non-specific, since it can be antagonized by divalent cations, but not by organic analogs, such as sugars or amino acids (Bryan et al., 1980). Gentamicin transport has also been shown to decline with falling $\mathrm{pH}$ (Bryan et al., 1980), an observation which would provide a good explanation of the declining antibacterial activity at acid $\mathrm{pH}$ referred to before. Finally, gentamicin transport is assumed to be common to several other aminoglycoside antibiotics (Bryan \& Van den Elzen, 1977; Bryan et al., 1980). It can be predicted that any defect in the transport of gentamicin by micro-organisms within abscesses, whether due to unfavourable $\mathrm{pH}$ or $\mathrm{pO}_{2}$ or both, will similarly affect the transport of all other aminoglycosides and consequently reduce their effectiveness. Although in-vivo defects in gentamicin transport can be predicted from in-vitro data (Bryan \& Van den Elzen, 1977; Bryan et al., 1980), experimental evidence for these defects is still lacking. Another consequence of the energy requirements for gentamicin transport is that any metabolic defect at the level of target bacteria which may reduce gentamicin accumulation will protect the variant bacteria from the bactericidal effect of gentamicin (Bryan \& Van den Elzen, 1977; Bryan et al., 1980) and of the other aminoglycoside antibiotics. The emergence of such insensitive variants during experimental or clinical therapy has been documented recently (Miller et al., 1980).

After having considered the possible physiological effects of $\mathrm{pH}$ or $\mathrm{pO}_{2}$ on the gentamicin antibacterial activity, we have to discuss a complex category of inhibitory substances, namely factors that bind gentamicin molecules, the presence of which reduces the concentration of the free, biologically active drug. This problem has been approached in vitro either by incubating purulent material with gentamicin (Bryant \& Hammond, 1974; Davis \& Bruns, 1978) or, by testing different groups of purified macromolecules for gentamicin (Deguchi, Ishii \& Tanaka, 1978) or neomycin (Potter, Matthews et al., 1965) binding activity. An intermediate approach was to study the binding of gentamicin to subcellular fractions of noninfected organs or tissues (Kunin, 1970; Kornguth, Bayer \& Kunin, 1980). The clinical relevance of these studies is as yet uncertain, because most of the results on gentamicin binding have been obtained under somewhat unphysiological conditions: either the gentamicin binding assays were performed in salt buffers of too low an ionic strength (Bryant \& Hammond, 1974; Kornguth et al., 1980), or the binding was assessed after the purulent samples had been strongly homogenized (Bryant \& Hammond, 1974; Davis \& Bruns, 1978). As will be seen later, both conditions may have considerably enhanced the gentamicin binding properties of the materials tested. Concerning the influence of the low ionic strength, it has been demonstrated that serial dilution of gentamicin, as required for radioimmunoassays, leads to strong adsorbance of the drug to the surface of the glass tubes when performed in low salt buffers (Josephson, Houle \& Haggerty 1979). This probably electrostatic interaction between the polycationic aminoglycoside and the negative charges of glass surfaces can be prevented by dilution of gentamicin in buffers of physiological ionic strength (Josephson et al., 1979). As another example of ionic strength-dependent binding of gentamicin, solutions of mucopolysaccharides were 
found to form complexes with this aminoglycoside very efficiently in buffers of a low ionic strength, but not at all in buffers of physiological strength (Deguchi et al., 1978). From these data, it can be predicted that unspecific gentamicin binding may occur in solutions of low ionic strength, by electrostatic interaction with a large range of anionic substances. The clinical significance of this phenomenon is unknown, but it implies that any in-vitro study of gentamicin binding will have to consider ionic strength carefully.

The effect of homogenizing the purulent material on the extent of gentamicin binding can be illustrated by our own data (Vaudaux \& Waldvogel, 1980), which shows a more than two-fold increase in [14 C]gentamicin binding after freezethawing of the material (Vaudaux \& Waldvogel, 1980). It is therefore possible that gentamicin and neomycin binding data were artificially enhanced in some previous studies, which used either purulent material lyophilized and suspended in distilled water (Potter et al., 1965), purulent sputum sonicated and autoclaved (Davis \& Bruns, 1978), or purulent exudates homogenized, frozen and diluted in water (Bryant \& Hammond, 1974).

\section{Personal results}

Gentamicin binding, however, cannot be accounted for only by a laboratory artefact: recent data obtained in our laboratory under well-controlled conditions have demonstrated that gentamicin binding and inactivation correlated with increased cell lysis of an exudate rich in polymorphonuclear leukocytes. Pus has often been described as being a zone of intense cellular destruction and necrosis. In a recent study, however, we showed that polymorphs from abscesses or pleural empyemas contained in some instances more than $10^{7} / \mathrm{ml}$ identifiable polymorphs with more than $60 \%$ of them excluding trypan blue (Vaudaux \& Waldvogel, 1980; Waldvogel et al., in press). Some of these viable cells were even shown to have significant phagocytic bactericidal activity, when incubated with properly opsonized bacteria in a standard in-vitro phagocytic bactericidal assay (Waldvogel et al., in press). Thus, it looks as if purulent exudates are composed of two types of polymorphs, some of them undergoing lysis, some of them intact. Further data from our laboratory, on gentamicin interaction with purified human polymorphs, have shown this interaction to be entirely different with intact or lysed leucocytes. Live purified polymorphs actively engulfing a test strain of Staphylococcus aureus Wood 46 , were able to protect ingested bacteria from extracellular gentamicin concentrations equal to 80 times their minimal bactericidal concentration in cell free medium (Vaudaux \& Waldvogel, 1979). As only a minimal amount (100 ng) of $\left[{ }^{14} \mathrm{C}\right]$ gentamicin was found to be associated with live polymorphs it was postulated that these intact leukocytes prevented the aminoglycoside antibiotic from accumulating inside the phagocytic cells and interacting with the target bacteria (Vaudaux \& Waldvogel, 1979).

In contrast, $10^{7}$ polymorphs $/ \mathrm{ml}$, after freezing-thawing, were found to be permeable to trypan blue and were able to bind a 100-fold larger amount $(10 \mu \mathrm{g})$ of $\left[{ }^{14} \mathrm{C}\right]$ gentamicin, when compared with intact, live cells. This binding was defined as the amount of antibiotic co-sedimenting $(3000 \mathrm{~g}$ for $10 \mathrm{~min})$ with particulate material from lysed polymorphs, after a preincubation period of $1 \mathrm{~h}$ at $37^{\circ} \mathrm{C}$ in PBS (Dulbecco's phosphate buffer saline solution). The particulate gentamicin binding 
material was finally identified as being the chromatin DNA of polymorphs. The failure of live polymorphs to bind gentamicin on their chromatin DNA was attributed to the impermeability of their intact membrane to this drug. When this observation was transposed to purulent exudates consisting of intact as well as lysed polymorphs in various proportions, a correlation was found between the concentration of trypan blue positive polymorphs and the in-vitro gentamicin binding of the material. When the proportion of trypan blue positive cells was increased to $>99 \%$ by either freeze-thawing of the purulent exudates or by suspension of purulent leucocytes in distilled water, increased lysis could account for the increased $\left[{ }^{14} \mathrm{C}\right]$ gentamicin binding previously mentioned (Vaudaux \& Waldvogel, 1980). From these findings, it can be stated that the extent of cell lysis, as well as the total polymorph concentration within purulent exudates, determines to a large extent the degree of gentamicin binding recorded in vitro. It is, however, still difficult to predict the extent of gentamicin binding occurring in vivo. Obviously, this question will need an in-vivo approach combined with some of the recently developed techniques of assessing cell concentration and viability, DNA contents of the cell suspension, and finally [ $\left.{ }^{14} \mathrm{C}\right]$ gentamicin binding, as estimated by either co-sedimentation with particulate chromatin or by ultrafiltration, with the low molecular weight chromatin fragments. The occurrence of polymorph chromatin fragments, possibly processed by nucleases released by pyogenic micro-organisms or by host cells within purulent exudates or abscesses, may play a significant role in gentamicin binding (unpublished results). This observation might explain why we found only $10 \%$ gentamicin co-sedimenting with particulate chromatin in those purulent exudates or abscesses showing the most extensive cell lysis and nuclear degradation (unpublished results).

\section{Conclusions}

Conditions of reduced $\mathrm{pH}$ and $\mathrm{pO}_{2}$, such as are found frequently within abscesses, may considerably reduce the antibacterial effect of gentamicin, possibly by their interfering action of gentamicin transport into the bacteria. In addition, binding factors in purulent exudates, such as leukocytic chromatin exposed to gentamicin after cell lysis, may bind a significant proportion of the total antibiotic, leading to an equivalent decrease of the concentration of the free, biologically active drug. How other anionic macro-molecules such as mucopolysaccharides might co-operate or interfere with the gentamicin-binding activity of chromatin DNA is presently unknown. However, intact phagocytes which do not bind gentamicin on their chromatin because of drug exclusion from the viable cells, protect ingested bacteria from being killed by large amounts of antibiotics. The role played by the different inactivating factors has yet to be defined in a clinical context, by analysis of experimental abscesses as an extension of the present in-vitro data.

\section{Acknowledgements}

I wish to thank Francis A. Waldvogel for reviewing the manuscript, and Françoise Michaud for secretarial assistance. 


\section{References}

Barber, M. \& Waterworth, P. (1966). Activity of gentamicin against Pseudomonas and hospital staphylococci. British Medical Journal i. 203-5.

Bryan, L. E., Haraphongse, R. \& Van den Elzen, H. M. (1976). Gentamicin resistance in clinical isolates of Pseudomonas aeruginosa associated with diminished gentamicin accumulation and no detectable enzymatic modification. Journal of Antibiotics (Tokyo) 29, 743-53.

Bryan, L. E. \& Van den Elzen, H. M. (1975). Gentamicin accumulation by sensitive strains of Escherichia coli and Pseudomonas aeruginosa. Journal of Antibiotics (Tokyo) 28, 698-703.

Bryan, L. E. \& Van den Elzen, H. M. (1977). Effects of membrane-energy mutations and cations on streptomycin and gentamicin accumulation by bacteria: a model for entry of streptomycin and gentamicin in susceptible and resistant bacteria. Antimicrobial Agents and Chemotherapy 12, 163-77.

Bryan, L. E., Kowand, S. K. \& Van den Elzen, H. M. (1979). Mechanism of aminoglycoside antibiotic resistance in anaerobic bacteria: Clostridium perfringens and Bacteroides fragilis. Antimicrobial Agents and Chemotherapy 15, 7-13.

Bryan, L. E., Nicas, T., Holloway, B. W. \& Crowthers, C. (1980). Aminoglycoside-resistant mutation of Pseudomonas aeruginosa defective in cytochrome C 552 and nitrate reductase. Antimicrobial Agents and Chemotherapy 17, 71-9.

Bryant, R. E. \& Hammond, D. (1974). Interaction of purulent material with antibiotics used to treat Pseudomonas infections. Antimicrobial Agents and Chemotherapy 6, 702-7.

Davis, S. D. \& Bruns, W. T. (1978). Effects of sputum from patients with cystic fibrosis on the activity in vitro of 5 antimicrobial drugs on Pseudomonas aeruginosa. American Journal of Respiratory Diseases 117, 176-8.

Deguchi, T., Ishii, A. \& Tanaka, M. (1978). Binding of aminoglycoside antibiotics to acidic mucopolysaccharides. Journal of Antibiotics (Tokyo) 31, $150-5$.

Dreznik, Z., Schwartzkopf, R., Wolfenstein, I. T. \& Rubinstein, E. (1979). Gentamicin penetration into abscesses. Current Chemotherapy and Infectious Disease. In The Proceedings of the 11th International Congress of Chemotherapy and the 19th InterScience Conference on Antimicrobial Agents and Chemotherapy, pp. 649-50. American Society of Microbiology.

Hays, R. C. \& Mandell, G. L. (1974). $\mathrm{pO}_{2}, \mathrm{pH}$, and redox potentials of experimental abscesses. Proceedings of the Society of Experimental Biology and Medicine 147, 29-30.

Josephson, L., Houle, P. \& Haggerty, M. (1979). Stability of dilute solutions of gentamicin and tobramycin, Clinical Chemistry 25, 298-300.

Kornguth, M. L., Bayer, W. H. \& Kunin, C. M. (1980). Binding of gentamicin to subcellular fractions of rabbit kidney: inhibition by spermine and other polyamines. Journal of Antimicrobial Chemotherapy 6, 121-31.

Kunin, C. M. (1970). Binding of antibiotics to tissue homogenates. Journal of Infectious Diseases 121, 55-64.

Miller, M. H., Edberg, S. C., Mandel, L. J., Behar, C. F. \& Steigbigel, N. H. (1980). Gentamicin uptake in wild-type and aminoglycoside-resistant small-colony mutants of Staphylococcus aureus. Antimicrobial Agents and Chemotherapy 18, 722-9.

Paisley, J. W. \& Washington, J. A. (1979). Susceptibility of Escherichia coli $\mathrm{Kl}$ to four combinations of antimicrobial agents potentially useful for treatment of neonatal meningitis. Journal of Infectious Diseases 140, 183-91.

Potter, J. L., Matthews, L. W., Spector, S. \& Lemm, J. (1965). Complex formation between basic antibiotics and deoxyribonucleic acid in pulmonary secretions. Pediatrics 36, 714-20.

Reynolds, A. V., Hamilton-Miller, J. M. T. \& Brumfitt, W. (1976). Diminished effect of gentamicin under anaerobic or hypercapnic conditions. Lancet $i, 447-9$.

Rosenblatt, J. E. \& Schoenknecht, F. (1972). Effects of several components of anaerobic incubation on antibiotic susceptibility test results. Antimicrobial Agents and Chemotherapy 1, 433-40. 
Sabath, L. D. \& Toftegaard, I. (1974). Rapid microassays for clindamycin and gentamicin when present together and the effect of $\mathrm{pH}$ and of each on the antimicrobial activity of the other. Antimicrobial Agents and Chemotherapy 6, 54-9.

Strausbaugh, L. J. \& Sande, M. A. (1978). Factors influencing the therapy of experimental Proteus mirabilis meningitis in rabbits. Journal of Infectious Diseases 137, 251-60.

Vaudaux, P. \& Waldvogel, F. A. (1979). Gentamicin antibacterial activity in the presence of human polymorphonuclear leucocytes. Antimicrobial Agents and Chemotherapy 16, 743-9.

Vaudaux, P. \& Waldvogel, F. A. (1980). Gentamicin inactivation in purulent exudates: role of cell lysis. Journal of Infectious Diseases 142, 586-93.

Waldvogel, F. A., Vaudaux, P., Lew, D. P., Zwahlen, A., Suter, S. \& Nydegger, U. E. Deficient phagocytosis secondary to breakdown of opsonic factors in infected exudates (in press).

Young, L. S. \& Hewitt, W. L. (1973). Activity of five aminoglycoside antibiotics in vitro against Gram-negative bacilli and Staphylococcus aureus. Antimicrobial Agents and Chemotherapy 4, 617-25. 